\title{
Academic Fatalism: Applying Durkheim's Fatalistic Suicide Typology to Student Drop-Out and the Climate of Higher Education
}

\author{
Brian P. Godor ${ }^{1}$
}

Received: 9 April 2016/ Accepted: 13 September 2016/Published online: 3 October 2016

(C) The Author(s) 2016. This article is published with open access at Springerlink.com

\begin{abstract}
Student drop-out remains a critical issue facing educational professionals. For higher education, the vast research in the past 40 years has been influenced by the work of Tinto and his model of student persistence. In this model are several elements that have proven to sharpen the focus of student drop-out research such as the concept of integration. The philosophical foundation for these concepts stems from Durkheim's work on suicide. Specifically, Tinto's employs Durkheim's "egotistical" suicide type as an analogy for student departure while attributing students' departure as a decision to separate themselves from the academic community. However; assigning causation of student departure to students' decisions stands in stark contrast to the theoretical underpinnings of Durkheim's work. Durkheim believed that certain social tendencies cause suicides. If student drop-out is to be typified by a certain Durkheimian suicide "type," then specific social facts must exist in those societies. In this article, student departure in higher education will be examined using Durkheim's theory of suicide complemented with Bourdieu's theory of symbolic violence. Egotistical suicide will then be re-examined as an analogy for student departure and the Durkheimian suicide "fatalistic" will be presented as suitable analogy for student departure.
\end{abstract}

Keywords Student drop out - Symbolic violence · Intergration - Social capital · Non-traditional students $\cdot$ Student persistence

Brian P. Godor

godor@fsw.eur.nl

1 Department of Psychology, Education and Child Studies, Erasmus University Rotterdam, Mandeville T13-39, Burg. Oudlaan 50, Postbus 1738 - 3000 DR, Rotterdam, The Netherlands 


\section{Introduction}

Student drop-out remains a critical issue facing educational professionals. For higher education, there is a long research tradition investigating this phenomenon. Such research foci has included: student involvement and academic success (Astin 1984), sociological underpinnings and student retention (Spady 1970), as well as the perceived utility of attending college for non-traditional students (Bean and Metzner 1985). However, the vast research in the past 40 years has been influenced by the work of Tinto. While Tinto's focus was the traditional campus (residential) universities that overwhelmingly serve full-time students, his model of student persistence contains several critical elements that have proven to sharpen the focus of student drop-out research such as the concept of student integration (social and academic), and research on student integration abounds (Bamber and Tett 2001; Berger and Milem 1999; Mannan 2007; McQueen 2009; Pascarella and Terenzini 1979a, 1983; Severiens and Schmidt 2008).

Additionally, Tinto's use of Durkheim's "egotistical" suicide type as an analogy for student departure has also greatly shaped research on student drop-out. According to Tinto (1975), student departure stems from the notion of "malintegration" as defined as both "one's holding values highly divergent from those of the social collectivity" and "insufficient personal interaction with other members of the collectivity" (p. 91). The effect of Tinto's perspective on student departure research has resulted in a focus on student-related characteristics such as non-productive integrative beliefs (holding deviating values) and lack of productive integrating behavior (not seeking personal interactions). More specifically, Tinto defines student departure as an action or "decision" on the part of the student to separate themselves from the academic community (Fig. 1).

This emphasis on student-related behaviors and student-related characteristics has functioned to drive research and, hence, has become the overwhelming focal point in student departure research. However, this approach fails to examine institution-related behaviors and institution-related characteristics such as the climate of academia. For example, issues such as "the institutional habitus" of a university (Thomas 2002), the pedagogic authority of institutions to control and sanction discourse (Grenfell 1998), the determination of appropriate participation (Hand 2012), and the acceptance of the perpetuation of the superior power position within the classroom of teachers (Bourdieu 1986, 1998; Bourdieu and Passeron 1990) all fall outside this dominant research focus.
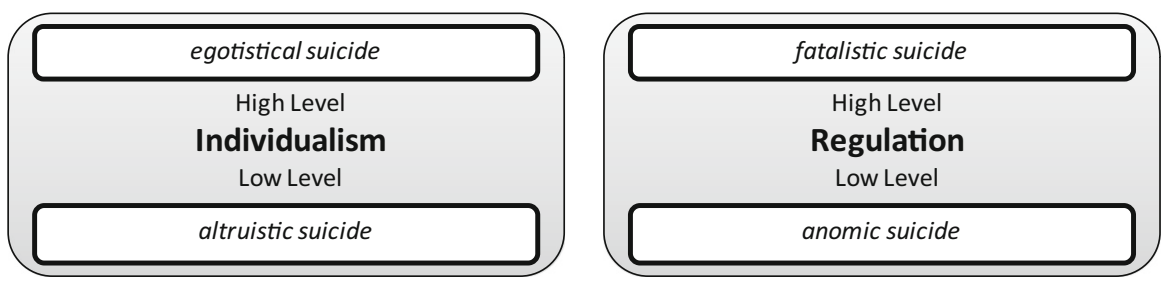

Fig. 1 Durkheim's two social forces 
But more fundamentally, assigning causation of student departure to individual (student) characteristics stands in stark contrast to the theoretical underpinnings of Durkheim's work on suicide. Durkheim asserted that certain social tendencies cause suicides in societies and not individual characteristics. If student drop-out is to be typified by a certain Durkheimian suicide "type," then certain social facts/tendencies must exist in those societies (academic communities) to cause these specific types of suicides; otherwise, according to Durkheim, these suicide types cannot occur in that society.

The focus of this article will be first to explore Durkheim's theoretical foundations of suicide. Following this, an exploration of the characteristics of academic communities (higher education) will be presented built upon Bourdieu's theory of symbolic violence. Combining these two theoretical perspectives, the theoretical appropriateness of egotistical suicide will be re-examined as an analogy for student departure. Consequently, Durkheim's fatalistic suicide types, will be presented as more suitable analogy for student dropout.

\section{Durkheim and Le Suicide}

Durkheim (1897/2006) argued that the subject matter of sociology should be "social facts" (Thompson 2002, p. 8). He asserts that "social facts must be studied as things, that is, as realities external to the individual" otherwise "if no reality exists outside of individual consciousness, it wholly lacks any material of its own" (Durkheim 1897/2006, p. 36) thus leaving only mental states to observe. These external realities can be defined as the social tendencies of a community. Stemming from this perspective, Durkheim's work on suicide strove to discover the "social causes" (p. 3) of suicide. He states that the "tendencies of the whole social body, by affecting individuals, cause them to commit suicide" (p. 264).

Durkheim's classification of suicide types was based upon on etiological (social forces) rather than morphological aspects (characteristics of the individual act of suicide). He believed that suicides were caused by the imbalances of two social forces in a society: "individualism" and "regulation". When these forces become imbalanced, the chance of specific types of suicide stemming from these imbalances increases. Durkheim states that disequilibrium is a social fact, a "collective phenomenon" (p. 97) of societies. For example, when the social force of "individualism" becomes imbalanced, two types of suicides become more prevalent: (1) egotistical suicide (high individualism), (2) altruistic suicide (low individualism). When the social force of regulation becomes imbalanced, two types of suicides become more prevalent: (1) fatalistic suicide (high regulation), (2) anomic suicide (low regulation).

\section{Durkheim's Suicide Theory in Educational Research}

Spady (1970) considered that the then-current work on student drop-out lacked "conceptual clarity, methodological rigor, complexity of design, breadth, and analytic sophistication" (p. 64). He maintained that research on student drop-out 
should move from having a focus on college success to "a more interdisciplinarybased, theoretical synthesis" of productive approaches (p. 64). A possible approach, according to Spady, was basing this new model on Durkheim's theory of suicide. Spady states:

Durkheim's theory of suicide provides a fruitful vehicle for summarizing a large proportion of current research, and focusing future attention on the interaction between student attributes (i.e., dispositions, interests, attitudes, and skills) and the influences, expectations, and demands imposed by various sources in the university environment (p. 64).

By bringing Durkheim's work and student drop-out research together, Spady attempted to develop a more "sociological model of the dropout process". Central to this new approach was the focus on the interaction between students' "dispositions, interests, attitudes, and skills" and "influences, expectations, and demands from a variety of sources including courses, faculty members, administrators, and peers". Spady also asserted that if a student does not have sufficient "normative congruence" and "friendship support" with the academic community, then students will break "one's ties with a social system" (p. 77). Tinto (1975) also noted that "research on dropout from higher education has also been marked by inadequate conceptualization of the dropout process" (p. 45).

Tinto suggested that, through the application of Durkheim's egotistical suicide type to student dropout, a deeper understanding of the process of student dropout could be gained. Tinto suggested that applying Durkheim's “egotistical” type of suicide to student dropout would provide a deeper understanding of the process of student dropout. In Leaving college: rethinking the causes and cures of student attrition, Tinto (1993) once again justifies his use of suicide as an analogy for student departure. According to Tinto, most suicides, as well as, student drop-out "represent a form of voluntary withdrawal" from a community. However, Tinto also states that suicides are "as much a reflection of the community as it is of the individual". Despite this assertion, his focus remains on students and their actions, stating that both suicide and student drop-out signal a rejection of the conventional norms (p. 99). In other words, according to Tinto, student departure is a volitional and intentional "decision" (1975, p. 97) chosen by students in order to renounce the traditional norms of the academic community.

In Tinto's (2012) latest book, Completing College: Rethinking Institutional Action, there seems to be a shift in his focus from the student-related behaviors and characteristics to institution-related behaviors and characteristics. Tinto states:

First, we must recognize that a college or university, once having admitted a student, has an obligation to do what it can to help the student stay and graduate. To improve retention and graduation, the institution must begin by focusing on its own behavior and establishing conditions within its walls that promote those outcomes (p. 6).

A framework for institutional action is outlined by four conditions for student success: expectations, support, assessment and feedback, and involvement. For "expectations," the institutional performance expectations of students, according to Tinto, need to be clear and consistent. "Support" mainly focuses on institutional 
initiatives that can help students' preparedness both academically and socially. "Assessment and feedback" centers on assessing incoming students for deficiencies, as well as feedback surrounding classroom assessments. Among the initiatives mentioned are student performance monitoring and signaling systems. Lastly, "involvement," as a condition for student success, refers to the quality of academic and social interactions. An interesting section contained in the chapter on involvement is "pedagogies of engagement" (p. 68). Problem based learning (PBL) and other cooperative and collaborative learning methods are discussed.

However, the underlying issues presented by Tinto (2012), together with the problems he addresses, and solutions offered, are predominantly focused on studentrelated behaviors. For example, the notion of "expectations" is built upon the premise that clearly and concisely communicated institutional expectations will increase student success. Clarity of expectations for student effort and what they should to do to succeed are given as examples. However, Tinto does not explicitly require institutions to examine the nature, validity, and appropriateness of these communications. Therefore, it might at first appear that Tinto is adopting both a social and individual perspective with regard to student drop-out. Whereas his applied focus effectively shifts the burden of accountability for student success back to the student

Similarly, "assessment and feedback" focuses on both assessing student's for pre-entry academic deficiencies and feedback concerning their current performance. However, the role and relevance of pre-entry academic deficiencies is not straightforward. In his own work, Tinto mentions that remedial courses also benefit students with strong academic skills, thus implying that the issue of student success and participating in remedial courses might be due less to the students' perceived pre-entry academic deficiencies and more due to the fact that support has been offered to students in the first year.

As for students' current performance, examples of early warning systems are presented. For example, if a student fails to come to class or does not log into the course management system, a warning can be generated to the teaching faculty. However, while Tinto calls for institutions to focus on their own behavior, these warning systems once again externally maneuver the foundations for student success from the institution itself back to the student, since it was the student who chose not to attend classes. And while learning analytics might be a good indicator for course success, so long as the essential question "Why is this student not coming to class?" remains unanswered, a solution to the problem-dropout—will not be discovered.

Employing Durkheimian suicide types might aid in discovering possible influences for student departure. However, this implies that we should be able to find, in academic communities in higher education, the presence of certain social tendencies to cause these suicides types to occur. In the following section, Bourdieu's theory of symbolic violence will be presented in order to discover which social factors are present within academic communities. 


\section{Egotistical Suicide}

According to Durkheim (1897/2006), when the social force of individualism is too high, Egotistical suicide will be present in those societies. Durkheim based his work on empirical data of suicide rates between Catholic and Protestant areas in Europe. Durkheim notes that, since both religions "prohibit suicide with equal emphasis" and "penalize it morally with great severity," a difference in attitude towards suicide cannot be a cause for either a higher or lower suicide rate between these two communities (p. 157). However, these two religions, according to Durkheim, hold different views with regard to the amount of "free inquiry" allowed. Protestantism permits personal inquiry and open interpretation, but Catholicism does not. However, the disadvantage for this open approach to religion is that the sense of being bound to a community by common beliefs and rituals is lost. This would be an example, according to Durkheim, of weak integration. This weak integration rooted in the individual freedom of inquiry makes a conscious departure from that community (i.e. suicide) easier.

\section{Fatalistic Suicide}

The other social force that Durkheim identified as a potential social cause of suicides is regulation. Durkheim posited two types of suicides can result from an imbalance of regulation. Anomic suicide is rooted in societies with a lack of regulation. Fatalistic suicide is can be found in societies with too much regulation. Stemming from the above analysis of academic communities, one can reason that a lack of individualism in academic communities is partly due to an over-regulation of students in pedagogical settings. Therefore, following Durkheim's reasoning, if suicide (drop-out) does occur in academic communities, is must be fatalistic. Durkheim (1897/2006) describes fatalistic suicide as deriving from "from excessive regulation, that of persons with futures pitilessly blocked and passions violently choked by oppressive discipline. To bring out the ineluctable and inflexible nature of a rule against which there is no appeal" (p. 239). In these societies individuals experience a high level of outside control. These societies have an overabundance of laws or norms: "Fatalistic suicide can be characterized as the impossibility of internalizing norms which are too constraining or illegitimate" (Alexander and Smith 2005, p. 71). Lockwood (1992) remarks: "Fatalism refers to hopes so narrowed and diminished that even life itself becomes a matter of indifference" (p. 38). Attempts at integration into a new community with a perceived oppressive dominant regulating culture could lead to the feeling that one's futures are "pitilessly blocked and passions violently choked by oppressive discipline" (Durkheim 1897/2006, p. 239).

\section{Exploring the Climate of Higher Education}

\section{Bourdieu's Theory of Symbolic Violence}

Bourdieu (1988, 1998; Bourdieu and Passeron 1990), a French sociologist, wrote extensively on social class, social mobility, power and social stratification. 
Education, and more specifically, the French educational system, was often the focus of his work. At the foundation of Bourdieu's work is the notion of symbolic violence. Bourdieu defines symbolic violence as: "every power which manages to impose meanings and to impose them as legitimate" (1990, p. 4). However, this violence is not perpetuated by a sort of dictator; rather the institution has been deemed legitimate by society, as a whole, and therefore is also complicit in these acts.

In relation to education, the legitimacy and imposition of meaning stems from the social-certification of academic qualifications (Bourdieu and Passeron 1990, p. 28). In other words, the legitimate power of educational institutes come from the social acceptance/requirement of their academic degrees and thus allowing educational institutes to impose "cultural arbitrary" (p. 5) meanings on students. "Educational institutions are able to determine what values, language and knowledge are regarded as legitimate" (Thomas 2002, p. 431). Some examples are: the notion that higher education students should be "independent learners" (Read et al. 2003, p. 270), as to who are the "kind of people who do mathematics" (Hand 2012, p. 234), what counts as "academic language" (Bourdieu and Passeron 1990, p. 117), and the undervaluation of students "tacit knowledge" (Meeuwisse et al. 2010, p. 532).

The imposition of these cultural arbitrary meanings is performed through "pedagogic acts" (Boudieu 1990, p. 5) by the educational institution. According to Bourdieu, the "truth" of pedagogic acts is misrecognized insofar as they are transubstantiations of the power relation between institutions and students into a legitimate authority for performing pedagogic acts. In other words, the dominant power position held by institutions over students creates the legitimacy and truth of curricula. These pedagogic acts "present a privileged object for analysis of the social basis of the paradoxes of domination and legitimacy" (Bourdieu and Passeron 1990, p. 15).

Pedagogic acts performed by the institution also presuppose a pedagogic authority. Students, in order to pass their course and receive a degree, need to succumb to these symbolically violent acts and academically perform according to the prescribed institutional expectations. This is similar to Tinto's first condition for student success in which institutional performance expectations of students should be made clear and transparent (2012).

The pedagogic authority of institutions is also strengthened by the institutions' ability to impose sanctions. Examples of such sanctions are: (1) Allowing students to progress to the next year of study after passing the assessment, (2) failing students when an attendance requirement is not met, and (3) awarding points to a report for correctly using a specific referencing convention and thus requiring students to perform these behaviors or risk negative sanctions (i.e. course failure or not receiving a diploma). These sanctions perform two functions: strengthening the effect of the pedagogic act by attributing a level of esteem, and consecrating the pedagogic act by securing that act as legitimate. However, this esteem and legitimacy only stem from the disproportionate amount of power of the institution which has been granted by society and thus students.

However, the pedagogic authority of institutions is also exercised in the classroom. For example, Hand (2012) specifically reports that the dispositions of 
mathematics teachers can greatly influence the moment-to-moment decisions of those teachers during their lessons by determining which "forms of participation [are] appropriate for the classroom" (p. 234). In other words, teachers' observations and their moment-to-moment decisions in the classroom were based on the dominant cultural norms of what a mathematics classroom should be like, and thus these observations and decisions serve to "act as powerful socializing agents" (p. 235) and are examples of Bourdieu's notion of pedagogically symbolical violent acts.

The characteristic of these violent symbolic acts can be described in simple terms: when students display behaviors that are deemed appropriate they receive a positive sanction from the teachers in the form of positive attention and a negative sanction would be attached to students' inappropriate behavior by receiving little or no attention. Bourdieu and Passeron (1990) exemplified this exact point:

To overwhelm one's pupils with affection, as American primary school teachers do, by the use of diminutives and affectionate qualifiers, by insistent appeal to an affective understanding, etc. is to gain possession of that subtle instrument of repression, the withdrawal of affection, a pedagogic technique which is no less arbitrary than corporal punishment or disgrace (1990, p. 17).

Additionally, students' examination behavior may be influenced to a point of feeling "forced to answer in the exam the way they [teachers] see it" (Nash 2003, p. 761). In this article, Nash outlines how mono-cultural views of knowledge can play a dominating role in classroom discourse and oblige students to accept a certain doctrine that may be contrary to their personal beliefs or knowledge. Nash's work demonstrates the two functions of sanctions. First, the pedagogic act (the examination) is strengthened by potential negative effects (sanctions) of failing, so students feel forced to answer in a certain manner. Second, the pedagogic act is consecrated since it is the only accepted discourse that will allow students to pass their course and receive their degree.

The above exemplified teacher-student discourse, according to Grenfell (1998), could be mistaken for "scaffolding" practices by teachers in the classroom. Grenfell describes a pedagogical situation where a teacher is assisting a pupil with a math problem. The pupil wrongly states an answer and since the pupil did not use the teachers' method the pupil is re-attended by the teacher back to the problem to try again.

At this point, the teacher does not investigate what thinking results in this utterance; rather she talks the pupil through (according to) her own (legitimate) method. Her intention to teach is more powerful than her intention to understand the pupil (Grenfell, p. 84).

Obviously the pupil's wrong answer should not be accepted. However, Grenfell notes that the larger point in this situation is whether or not the teacher is effective in her teaching by striving to teach instead of to understand the pupil. Grenfell elaborates on this point by stating: 
One might say that what she is doing is good "scaffolding" without saying whether this is a good thing or not, for it puts the teacher in the superordinate position and gives legitimacy to her method and knowledge without accounting for the pupil's (p. 84).

Every pedagogical act is situated in a "field" (Bourdieu and Passeron 1990). This field is made up of actors (teachers and students) and is characterized by the various power relationships in that field. Teachers have the dominant power, but students have only certain powers in the classroom. It is these power struggles that define the classroom. These struggles are aimed to "occupy the dominant positions" (Bourdieu 1998, p. 264) in the field. Each of the actors in this, or any, field employ "strategies aimed at preserving or transforming these relations of power" (p. 265). In the above scenario described by Grenfell (1998), the teacher, by continuing to teach and impose her will on the student, uses her power in the situation to preserve her position (her method as legitimate). This is an example of what Bourdieu and Passeron (1990) meant by "symbolic violence": "to impose meanings and to impose them as legitimate by concealing the power relation" (p. 4).

\section{Analogies for Student Departure}

\section{Egotistical Suicide Re-Visited}

In order for egotistical suicide to be used an analogy for student departure from academic communities in higher education, a high level of individualism needs to be a feature of these communities. Difficulties are raised when trying to typify student departure based upon the premise that it is an egotistical act rooted and consecrated by students' free inquiry afforded to them within the academic community. Conversely, as outlined above, there seems to be a lack of space for students' free inquiry within the academic community. Examples are the controlling and sanctioning of discourse (Grenfell 1998), determining appropriate participation (Hand 2012), forcing students to accept facts that may be contrary to their personal beliefs (Nash 2003) and allowing teachers to perpetuate their superior power position within the classroom (Bourdieu 1986, 1998; Bourdieu and Passeron 1990). Having noted the lack of free inquiry in academic communities in higher education and thus a low level of individualism, egotistical suicide type seems an unlikely analogy for student departure when applying Durkheim's social criteria for suicide.

\section{Fatalistic Suicide}

Students coming from backgrounds lacking in familiarity with higher education can find the academic community in higher education "bewildering" (Meeuwisse et al. 2010) and "alien and unsettling" (Read et al. 2003). This lack of familiarity does not only concern familiarity in terms of formal content, social culture or academic language, but can also be in terms of the actual "field" (Bourdieu 1986, 1998; Bourdieu and Passeron 1990) that students need to interact: for example: a lecture 
hall with 800 students, computer labs with more than 1000 PCs, and a modern library with full multimedia services. Additionally, Read et al. also note that this alienation is not solely due to the fact that traditional students outnumber nontraditional students on campus. At institutions where there was "significant numbers of students of the same age, class and/or ethnicity" (p. 270), non-traditional students still felt a sense of alienation and isolation. It is possible that this sense of nonbelonging stems less from specific student-related characteristics and more from the "institutional habitus" of the university (Thomas 2002) As Read et al. remark:

Firstly, the student experiences institutional 'controls' through, for example, the 'regulated communications' of the lecture, the essay and the examination, and the rewards and punishments of the grading system. Secondly, the student is constrained by her or his own 'knowledge' of what it is to be a 'good' student, a knowledge which has been constructed through socially dominant discourses, including those produced and maintained by the university itself. Such 'knowledges' and practices are legitimated by their 'naturalization': they come to be seen as the only or 'natural' way of thinking or acting (2003, p. 269).

Thomas (2002) also concludes that "educational institutions are able to determine what values, language and knowledge are regarded as legitimate" (p. 431). If non-traditional students feel that their knowledge is undervalued and that they hold inappropriate cultural norms and practices, then, she argues, they may be more likely to drop out.

Additionally, if the regulation in academic communities is perceived by students as too constraining or illegitimate, then suicide in these societies "can be characterized as the impossibility of internalizing norms" (Alexander and Smith 2005, p. 71). However, for these students, there is a real tension between a sense of over-regulation and the need or desire to earn a degree. In other words, attempts at integration into a new academic community with a dominant over-regulating culture could lead to students from non-traditional educational backgrounds feeling that their futures are "pitilessly blocked and passions violently choked by oppressive discipline" (Durkheim 1897/2006, p. 239).

\section{Academic Fatalism}

The important role that student engagement plays in academic success has been well demonstrated (Hockings et al. 2007; Horstmanshof and Zimitat 2007; Hu et al. 2008; Kuh et al. 2008; Mann 2011; Svanum and Bigatti 2009). However, a creditable tension is created between student engagement and the dominant culture of academic communities in order for students to earn their degree. All students have personal characteristics that play a role in the level of student engagement. The culmination of those factors plays a central role in determining engagement and eventually comes to form the expectations that students hold in reference to attending higher education as well as studying. Konings et al. (2008) assert that expectations influence "investment of effort in learning" (p. 536). 
However, for non-traditional students, their "accumulated history" (Bourdieu 1986, p. 46) can greatly differ between traditional and non-traditional students. "For conventional students, passing through HE [higher education] can be a relatively smooth, integrative process involving confirmation of what they already know and hold to be true" (Bamber and Tett 2001, p. 59). Conversely, non-traditional students generally report a sense of otherness (Read et al. 2003). As Meeuwisse (2012) notes, academic success for non-traditional students is not just a case of being smart enough, but there are many other complex psychological elements that are critical for academic success for these students.

Durkheim's theoretical foundation of suicide is built upon the central notion that suicide is caused by social facts/tendencies not found in individuals, but in societies themselves. Therefore to employ an analogy in order to gain a deeper understanding of non-traditional student drop-out, the social facts existing in academic communities that cause these dropouts need to be identified. The social facts are those characteristics of academic communities that can be perceived as constraining or illegitimate by students and that lead students feeling that their futures are blocked and personal passions are oppressed.

\section{Conclusion}

Given the fact that student drop-out remains a critical issue still facing educational professionals, the need for "conceptual clarity, methodological rigor, complexity of design, breadth, and analytic sophistication" remains as relevant today as when Spady stated this more than 40 years ago. The intervening period has seen the development of critical concepts concerning student persistence such as student integration (social and academic) and research on student integration. Research on student drop-out has been greatly influenced by these concepts. However, this research has tended to focus on student-related behaviors and characteristics, thus ignoring the many institutionrelated behaviors and institution-related characteristics.

As explained above, Durkheim's causes for egotistical suicide were certain tendencies to be found in society and not individual acts. This fact disqualifies egotistical suicide as an analogy for student drop-out if it is solely used to investigate student-related behaviors and student-related characteristics that might lead to "malintegration" (holding deviating values) and lack of productive integrating behavior (not seeking personal interactions) (cf. Tinto 1975, p. 91).

Additionally, the student retention research aim has shifted the a focus on student drop-out and persistence to the current narrative focusing on student engagement. This shift can be characterized as a move to a more positive means of discussing this issue, rather than the negative tone of student drop-out or lack of student persistence. However, the change in the narrative's perspective, in my opinion, actually reinforces many of the above mentioned points. By discussing and researching student engagement, the focus is once again not directly on the community or society (higher education), but it is placed back on the individual (the student). By reviving Durkheim's notion that suicide is caused by tendencies found in communities themselves and combining that with an investigation of academic 
communities in higher education through social capital theory leads to the emergence of a new possible analogy for student drop-out: fatalistic suicide.

The formal academic community's culture could lead students to feel over regulated due to a high level of outside academic control. This perceived overregulation is characteristic of Durkheim's "fatalistic suicide" type. This overregulation could stem from educational institutions' ability to deem which values, discourse and knowledge is valid combined with institutions' legitimate power stemming from the social acceptance and requirement of their academic degrees. Moreover, by universities not formally codifying other "knowledges" actually leads to a perpetuation of the inequalities currently found in modern universities as well as, the society as a whole. For example, the requirement for students to pass certain examinations, in a certain way, using certain language in order to be still eligible for an academic degree will lead to feelings of being blocked. These are characteristic of fatalistic suicide, and generally illustrate the experiences of students coming from backgrounds without any knowledge of higher education.

\section{Compliance with Ethical Standards}

Conflicts of interest The author asserts that there are no potential conflicts of interest and that he is the sole author of the manuscript.

Open Access This article is distributed under the terms of the Creative Commons Attribution 4.0 International License (http://creativecommons.org/licenses/by/4.0/), which permits unrestricted use, distribution, and reproduction in any medium, provided you give appropriate credit to the original author(s) and the source, provide a link to the Creative Commons license, and indicate if changes were made.

\section{References}

Alexander, J. C., \& Smith, P. (2005). The Cambridge companion to Durkheim (1st ed.). Cambridge: Cambridge University Press.

Astin, A. W. (1984). Student involvement: A developmental theory for higher education. Journal of College Student Development, 40(5), 518-529.

Bamber, J., \& Tett, L. (2001). Ensuring integrative learning experiences for non-traditional students in higher education. Widening Participation and Lifelong Learning, 3(1), 8-16.

Bean, J. P., \& Metzner, B. S. (1985). A conceptual model of nontraditional undergraduate student attrition. Review of Educational Research, 55(4), 485-540.

Berger, J. B., \& Milem, J. F. (1999). The role of student involvement and perceptions of integration in a causal model of student persistence. Research in Higher Education, 40(6), 641-664.

Bourdieu, P. (1986). The forms of capital. In J. G. Richardson (Ed.), Handbook of theory and research for the sociology of education. New York: Greenwood Press.

Bourdieu, P. (1988). Homo academicus. Cambridge: Polity Press.

Bourdieu, P. (1998). The state nobility: Elite schools in the field of power (1st ed.). Stanford, CA: Stanford University Press.

Bourdieu, P., \& Passeron, J.-C. (1990). Reproduction in education, society and culture. (R. Nice, Trans.), (2nd ed.). London: Sage.

Durkheim, E. (1897/2006). Suicide, a study in sociology. Glencoe, Il: Free Press.

Grenfell, M. (1998). Language and the classroom. In M. Grenfell \& D. James (Eds.), Bourdieu and education: Acts of practical theory (1st ed., pp. 72-88). Hong Kong: Routledge.

Hand, V. (2012). Seeing culture and power in mathematical learning: toward a model of equitable instruction. Educational Studies in Mathematics, 80(1-2), 233-247. doi:10.1007/s10649-012-9387-9. 
Hockings, C., Cooke, S., \& Bowl, M. (2007). "Academic engagement" within a widening participation context-A 3D analysis. Teaching in Higher Education, 12, 721-733.

Horstmanshof, L., \& Zimitat, C. (2007). Future time orientation predicts academic engagement among first-year university students. British Journal of Educational Psychology, 77(3), 703-718.

Hu, S., Kuh, G. D., \& Li, S. (2008). The effects of engagement in inquiry-oriented activities on student learning and personal development. Innovative Higher Education, 33(2), 71-81.

Konings, K. D., Brand-Gruwel, S., van Merrienboer, J. J. G., \& Broers, N. J. (2008). Does a new learning environment come up to students' expectations? A longitudinal study. Journal of Educational Psychology, 100(3), 535-548.

Kuh, G. D., Cruce, T. M., Shoup, R., Kinzie, J., \& Gonyea, R. M. (2008). Unmasking the effects of student engagement on first-year college grades and persistence. Journal of Higher Education, 79(5), 540-563.

Lockwood, D. (1992). Solidarity and schism: The problem of disorder in Durkheimian and Marxist sociology. Oxford: Oxford University Press.

Mann, S. J. (2011). Alternative perspectives on the student experience: Alienation and engagement. Studies in Higher Education, 26(1), 7-19.

Mannan, M. A. (2007). Student attrition and academic and social integration: Application of Tinto's model at the University of Papua New Guinea. Higher Education, 53(2), 147-165.

McQueen, H. (2009). Integration and regulation matters in educational transition: A theoretical critique of retention and attrition models. British Journal of Educational Studies, 57(1), 70-88.

Meeuwisse, M. (2012). Being smart is not enough: The role of psychlogical factors in study success of ethnic minority and ethnic majority students. http://repub.eur.nl/pub/32035.

Meeuwisse, M., Severiens, S. E., \& Born, M. P. (2010). Learning environment, interaction, sense of belonging and study success in ethnically diverse student groups. Research in Higher Education, 51(6), 528-545. doi:10.1007/s11162-010-9168-1.

Nash, R. (2003). Progress at school: Pedagogy and the care for knowledge. Teaching and Teacher Education, 19(7), 755-767. doi:10.1016/j.tate.2003.02.001.

Pascarella, E. T., \& Terenzini, P. T. (1979). Interaction effects in Spady and Tinto's conceptual models of college attrition. Sociology of Education, 52(4), 197-210.

Pascarella, E. T., \& Terenzini, P. T. (1983). Predicting voluntary freshman year persistence/withdrawal behavior in a residential university: a path analytic validation of Tinto's model. Journal of Educational Psychology, 75(2), 215-226.

Read, B., Archer, L., \& Leathwood, C. (2003). Challenging cultures? Student conceptions of "belonging" and "isolation" at a post-1992 university. Studies in Higher Education, 28(3), 261-277.

Severiens, S. E., \& Schmidt, H. G. (2008). Academic and social integration and study progress in problem based learning. Higher Education, 58(1), 59-69.

Spady, W. (1970). Dropouts from higher education: An interdisciplinary review and synthesis. Interchange, 1(1), 64-85. doi:10.1007/BF02214313.

Svanum, S., \& Bigatti, S. M. B. (2009). Academic course engagement during one semester forecasts college success: Engaged students are more likely to earn a degree, do it faster, and do it better. Journal of College Student Development, 50(1), 120-132. doi:10.1353/csd.0.0055.

Thomas, L. (2002). Student retention in higher education: The role of institutional habitus. Journal of Education Policy, 17(4), 423-442.

Thompson, K. (2002). Emile Durkheim (2nd ed.). London: Routledge.

Tinto, V. (1975). Dropout from higher education: A theoretical synthesis of recent research. Review of Educational Research, 45(1), 89-125.

Tinto, V. (1993). Leaving college: Rethinking the causes and cures of student attrition. London: University of Chicago Press.

Tinto, V. (2012). Completing college: Rethinking institutional action. London: University of Chicago Press. 